\title{
Alteration of Feeding and Filtering Rates of Two Species of Marine Copepods Exposed to Different pH Levels
}

\author{
Yanqun Wang \\ College of Marine Life Sciences, Ocean University of China. Qingdao, Shandong \\ Province, 266003 \\ Laboratory for Marine Ecology and Environmental Science, Qingdao National \\ Laboratory for Marine Science and Technology, Qingdao 266071, China \\ Tel: 17863961493 \\ E-mail: 583198167@qq.com
}

Boyuan Wang

College of Marine Life Sciences, Ocean University of China. Qingdao, Shandong Province, 266003

Laboratory for Marine Ecology and Environmental Science, Qingdao National Laboratory for Marine Science and Technology, Qingdao 266071, China

Tel: 13791987185

E-mail: 624013735@qq.com

Ze Xue

College of Marine Life Sciences, Ocean University of China. Qingdao, Shandong Province, 266003

Tel: 13001696000

E-mail: wangyou@ouc.edu.cn

Liyan Zhu (Corresponding author)

College of Marine Life Sciences, Ocean University of China. Qingdao, Shandong Province, 266003

Tel: $13506391037 \quad$ E-mail: lyzhu@ouc.edu.cn

Received: May 4, 2019 Accepted: May 5, 2019 Published: May 19, 2019

doi:10.5296/ast.v7i2.14738 URL: https://doi.org/10.5296/ast.v7i2.14738

\begin{abstract}
Impacts of different $\mathrm{pH}$ levels on different species of marine copepods, Calanoida copepod Schmackeria poplesia and Cyclopoida copepod Oithona similis were evaluated, and the alteration of key physiological processes of feeding and filtering were comparatively studies under controlled lab conditions. The optimal pH for O.similis and S.poplesia was 9.0 and 8.0
\end{abstract}


respectively, and they performed differently when exposed to different $\mathrm{pH}$ levels. For $S$. poplesia., the feeding and filtering rates increased steadily with the increment of $\mathrm{pH}$ at the range of 6.0 8.0, and reached the peak at $\mathrm{pH} 8.0$. However, the rates decreased when $\mathrm{pH}$ was above 9.0. O.similis seemed more adaptive to the change of $\mathrm{pH}$, and the increment was found in feeding and filtering rates at a range of 6.0 8.0. The maximus appeared at $\mathrm{pH} 9.0$. compared to the other $\mathrm{pH}$ levels, the acidifying level of $\mathrm{pH} 6.0$ presented the most obviously inhibition on feeding and filtering. Results in the present study would shed light on establishing the optimum culturing conditions for the cultivation of marine copepod.

Keywords: $\mathrm{pH}$ level; feeding, filtering; marine copepod

\section{Introduction}

Globing warming have led to a decrease in both $\mathrm{pH}$ and the availability of ions in seawater, which is known as ocean acidification (Orr et al., 2005). This ongoing process has been proved to exerted negative impacts on different marine biota, and has been mostly devoted to organisms that depend on the availability of carbonate ions in seawater such as bivalves. Despite a growing number of studies published on the negative impacts induced by seawater acidification on key physiological processes including growth and reproduction, metabolism, immune function and calcification on bivalves (Sun et al., 2016; Xu et al., 2016), less information available regarding interference in marine zooplankton exposed to such scenarios because most of them are non-calcifying organisms. Marine copepods are important zooplanktonic biota. They are the key loop between primary producers and higher trophic levels and play essential role in stability and sustainability of the marine ecosystem, and growth, without any doubt, is critical to the population dynamics and biomass fluctuation. Besides, they are small, short life cycle and vulnerable to the environmental changes, which make them desirable organism models in the field of environmental toxicology. We thus performed the present study, aiming at elucidating the impacts of different $\mathrm{pH}$ level, especially that leading to acidification, on key physiological processes of feeding and filtering in marine copepod. Results would shed light on establishing the optimum culturing conditions for the cultivation of marine copepod.

\section{Materials and Methods}

\subsection{Organism Collection and Cultivation of Two Species of Marine Copepod}

Adult individuals of Schmackeria poplesia and Cyclopoida copepod Oithona similis were collected from the shrimp pond located in Qingdao, Shandong province using a small plankton net. The copepod samples were stored in $25 \mathrm{~L}$ polyvinyl chloride barrels and quickly transferred into lab conditions with $2 \mathrm{~h}$ after collection. The active and healthy individuals with good phototaxis were chosen and were kept in $2 \mathrm{~L}$ beaker containing raw seawater with continuous aeration for acclimation. The cultivating system was kept at $5 \sim 10{ }^{\circ} \mathrm{C}$ with a $12 \mathrm{~h}$ light: dark cycle in illuminating incubators with a light intensity of 700 Lux, and the salinity was set at 30 . Different bait mixture was applied for the acclimating cultivation: mixture of Isochrysis galbana: Chlorella sp.: Phaeodactylum tricornutu at a ratio of 3:1:1 was used for S. poplesia, and that of I. galbana: Thalassiosira weissflogii: 
Platymonas hellgolandica at the same ratio was for $O$. similis. The biomass of the bait was controlled within $10^{4} \mathrm{cells} / \mathrm{mL}$. After acclimation, the female individuals with eggs were picked up and were transferred into the $1 \mathrm{~L}$ beaker, and the temperature was steadily increased to $15^{\circ} \mathrm{C}$. The larvae were collected every other day to obtain the first-generation offspring and developed them to the adult for further experiment. The other cultivating conditions were the same as above described without other description. The microalgal cultivation was performed according to the method of Zhao et al. (2017), and the raw material was treated and sterilized according to the procedure of Zhang et al. (2015).

\subsection{Experimental Design}

The experiment was conducted in clean beakers containing raw seawater with $\mathrm{pH}$ values of 6.0、7.0、8.0 (control group) and 9.0, respectively. $\mathrm{HCl}$ and $\mathrm{NaOH}$ at a concentration of $1 \mathrm{M}$ was used to adjust the $\mathrm{pH}$ values. 10 adult copepods without eggs were randomly picked out and were placed into cultivating system above mentioned for 3 days. Thereafter, examination on feeing and filtering was performed according to the method of description of Castellani et al. (2005), and no feeding was performed during the experiment. The feeding and filtering rates were calculated according to the following equations (Frost, 1972):

$$
\begin{gathered}
\mathrm{F}=V / N \cdot \log _{\theta}(C t / C t f) \\
\mathrm{G}=F(C t f-C 0) / \log _{\theta}(C t f / C o)
\end{gathered}
$$

where ' $V$ ' is the total experimental volume $(\mathrm{mL})$; ' $N$ ' is the number of the copepod in each beaker (ind); ' $t$ ' is the duration (h) of the experiment; ' $c_{0}$ ' and ' $c c_{t}$ ' denote the cell densities in each flask at the beginning and at time ' $t$ ' after exposure in the control group, respectively; ' $c_{t f}$ ' is the final density in the treated groups.

\subsection{Statistic Analysis}

SPSS Statistics 17.0 was used to analyze the data. The difference between the test and control results were analysed statistically with one-way analysis of variance (one-way ANOVA).

\section{Results}

\subsection{Effects of Different pH Levels on Feeding and Filtering Rates of S. Poplesia}

The feeding and filtering rates of $S$. poplesia presented the similar changing tendency at the range of $\mathrm{pH}$ 6.0 9.0, which increased firstly and then decreased. Their lowest rates appeared at $\mathrm{pH}$ 6.0, which was the typical condition of seawater acidification. A relative increment was found thereafter and reached the peak at $\mathrm{pH}$ 8.0, which was set as the control in the present study. The further elevation of $\mathrm{pH}$ would significantly decrease the rates, inferring the occurrence of inhibition on metabolism. 

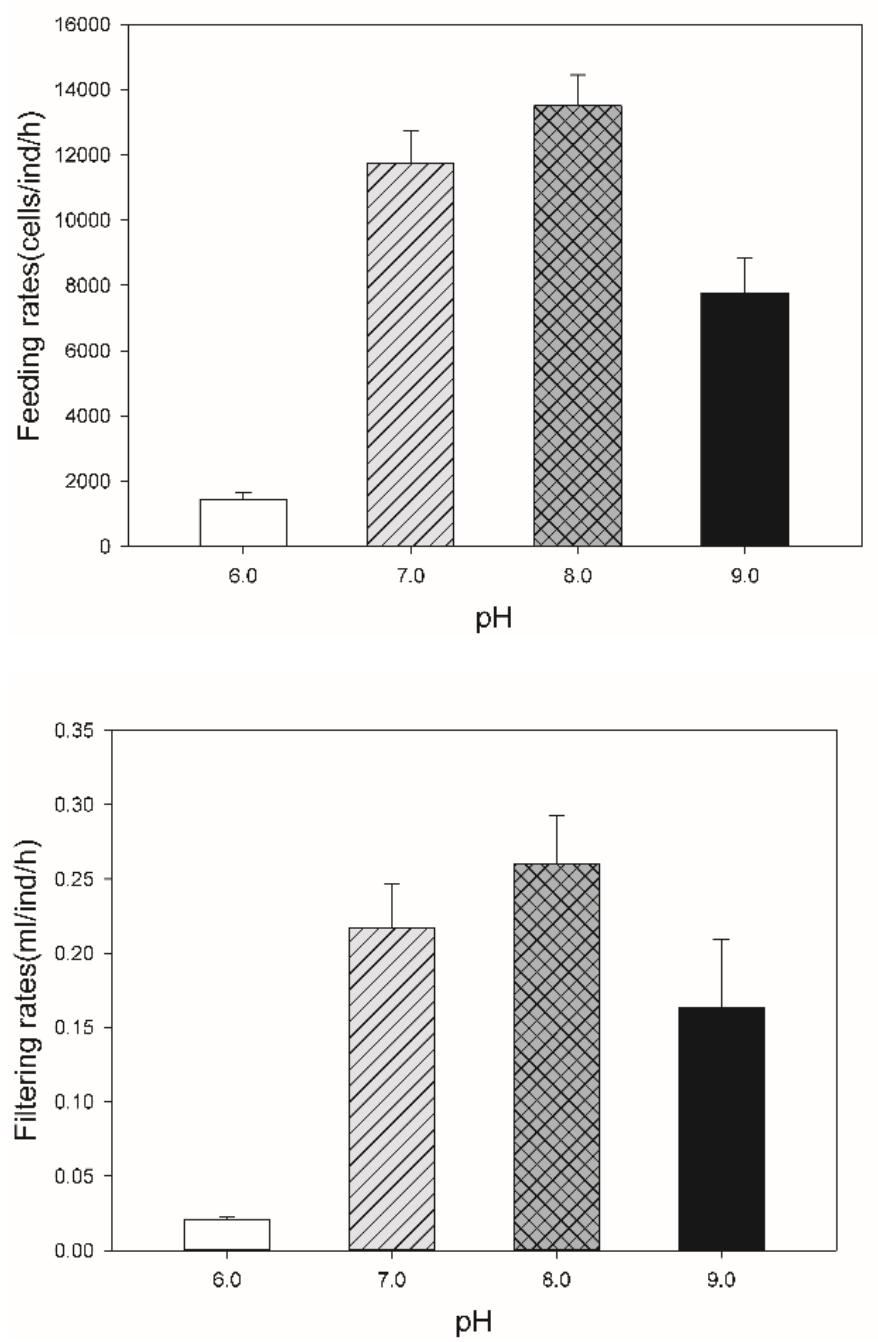

Figure 1. Effect of different $\mathrm{pH}$ levels on feeding and filtering rates of S. poplesia

\subsection{Effects of Different pH Levels on Feeding and Filtering Rates of O.Similis}

Different to those in S. poplesia, the feeding and filtering rates in O.similis increased steadily during the whole treatment, and the peak appeared at $\mathrm{pH}$ 9.0. Significance was observed between the treated group of $\mathrm{pH} 9.0$ and $\mathrm{pH}$ 6.0. it seemed that $O$.similis was more adaptive to the alteration of $\mathrm{pH}$ levels compared to $S$. poplesia. 

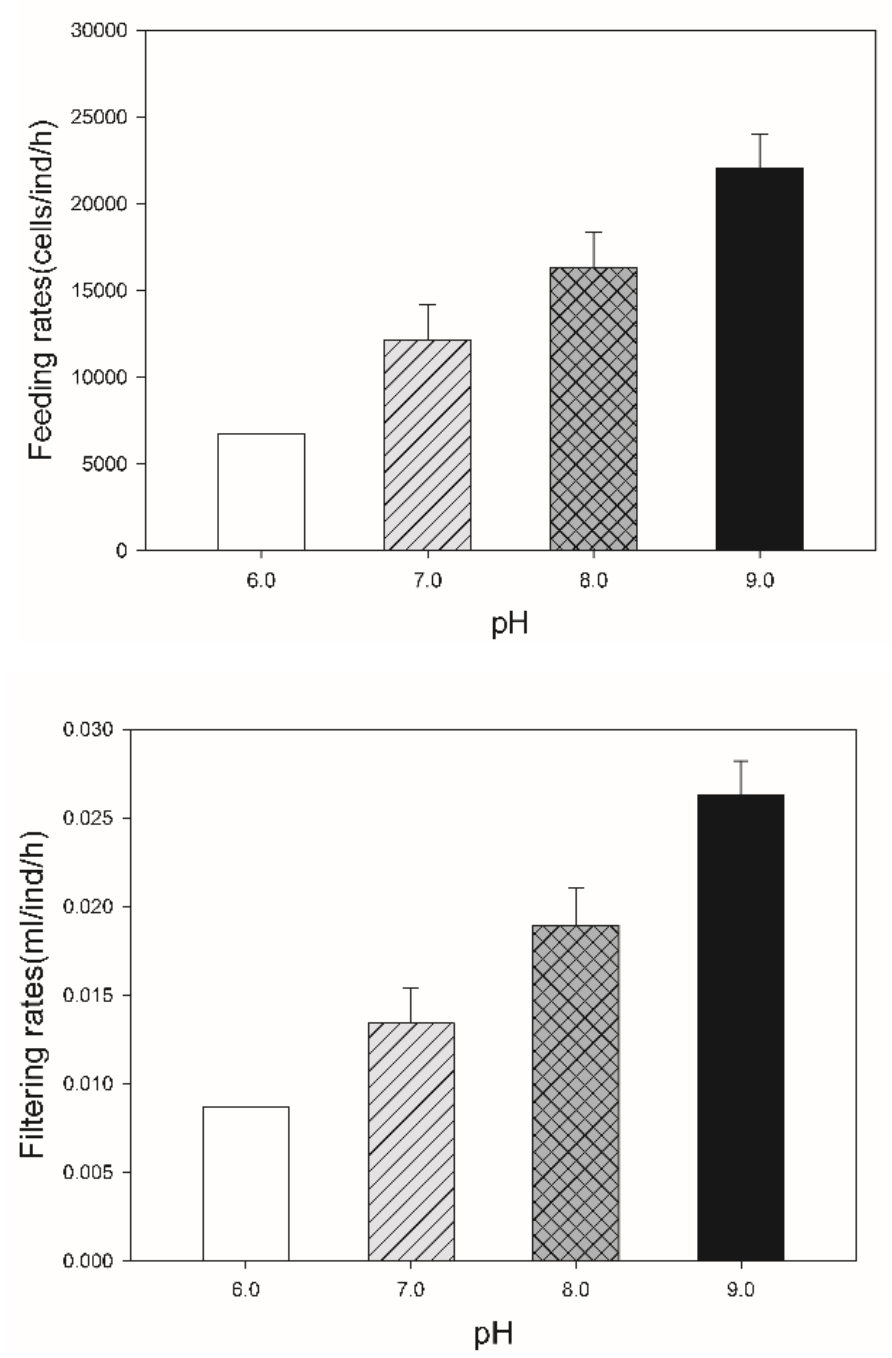

Figure 2. Effect of different $\mathrm{pH}$ levels on feeding and filtering rates of O.similis

\section{Discussion}

We found in the present study that the alteration of $\mathrm{pH}$ level significantly affected the feeding and filtering rates of two species of marine copepod, and $\mathrm{pH}$ at seawater acidification level seemed to exert negative impacts on them. This results were similar to the previous studies, which reported that seawater acidification interfered with feeding, metabolism and reproductive development of many zooplanktonic biota (Kurihara et al, 2008; Maar et al., 2012). Moreover, O.similis present more tolerance to the decreased $\mathrm{pH}$ as compared to $S$. poplesia. The obtained documents on 7 species of marine copepods had showed that the $24 \mathrm{~h}$ $\mathrm{LC}_{50}$ for seawater acidification induced by $\mathrm{HCl}$ addition was about 5. 02 5. 69, and a great difference was found among the species with different growth habit. For instance, the benthic copepod was the most tolerant one, and the phytophagous species was more tolerant than carnivorous ones. Moreover, the swimming ability of copepods also helps them avoid acidified environment (Thistle, 2007). When combined considered the results in the present study, we presumed that seawater acidification would interfere with the growth and metabolism of marine copepod, and different species exhibited various performance to the 
$\mathrm{pH}$ alteration. Results in the present study would be helpful for establishing an optimal system for copepod cultivation.

\section{Acknowledgements}

This study was financially supported by the National Natural Science Foundation (NSFC) of China (Nos. 31572621), the NSFC-Shandong Joint Fund for Marine Ecology and Environmental Sciences (No. U1606404). The authors were thankful to all the members in the lab for their assistance.

\section{References}

Castellani, C., Irigoien, X., Harris, R. P., \& Lampitt, R. S. (2005). Feeding and egg production of Oithona similis in the North Atlantic. Marine Ecology-Progress Series, 288, 173-182. https://doi.org/10.3354/meps 288173

Frost, B. W. (1972). Effects of size and concentration on the feeding behavior of the marine planktonic copepod Calanus pacificus. Limnology and Oceanography, 17, 805-815. https://doi.org/10.4319/lo.1972.17.6.0805

Kurihara, H., \& Ishimatsu, A. (2008). Effects of high $\mathrm{CO}_{2}$ seawater on the copepod (Acartia tsuensis) through all life stages and subsequent generations. Marine Pollution Bulletin 56, 1086-1090. https://doi.org/10.1016/j.marpolbul.2008.03.023

Maar, M., Møller, E. F., Gürkan, Z., Jónasdóttir, S. H., \& Nielsen, T. G. (2012). Sensitivity of Calanus spp. copepods to environmental changes in the North Sea using life-stage structured models. Progress In Oceanography. https://doi.org/10.1016/j.pocean.2012.10.004

Orr, J. C., Fabry, V. J., Aumont, O. et al., (2005). Anthropogenic ocean acidification over the twenty-first century and its impact on calcifying organisms. Nature, 437, 681-686. https://doi.org/10.1038/nature04095

Sun, T., Tang, X., Zhou, B., \& Wang, Y. (2016). Comparative studies on the effects of seawateracidification caused by $\mathrm{CO}_{2}$ and $\mathrm{HCl}$ enrichment on physiological changes in Mytilus edulis. Chemosphere 144, 2368-2376.

https://doi.org/10.1016/j.chemosphere.2015.10.117

Thistle, D., Sedlacek, L., Carman, K. R., et al., (2007). Emergence in the deep sea: Evidence from harpacticoid copepods. Deep Sea Research Part I: Oceanographic Research Papers, 54(6), 0-1014. https://doi.org/10.1016/j.dsr.2007.03.002

Xu, X., Yang, F., Zhao, L., \& Yan, X. (2016). Seawater acidification affects the physiological energetics and spawning capacity of the Manila clam Ruditapes philippinarum during gonadal maturation. Comp. Biochem. Physiol. A. Mol. Integr. Physiol. 196, 20-29. https://doi.org/10.1016/j.cbpa.2016.02.014

Zhang, X. X., Tang, X. X., Zhou, B., Hu, S. X., \& Wang, Y. (2015). Effect of enhanced UV-B radiation on photosynthetic characteristics of marine microalgae Dunaliella salina (Chlorophyta, Chlorophyceae), Journal of Experimental Marine Biology and Ecology, 469, 


\section{Macrothink}

27-35. https://doi.org/10.1016/j.jembe.2015.04.002

Zhao, Y., Wang, Y., Li, Y. J., \& Quigg, A. (2017). Response of photosynthesis and the antioxidant defense system of two microalgal species (Alexandrium minutum and Dunaliella salina) to the toxicity of BDE-47. Marine Pollution Bulletin, 124, 459-469. https://doi.org/10.1016/j.marpolbul.2017.07.038

\section{Copyrights}

Copyright for this article is retained by the author(s), with first publication rights granted to the journal.

This is an open-access article distributed under the terms and conditions of the Creative Commons Attribution license (http://creativecommons.org/licenses/by/4.0/) 